\title{
Risk factors for implant failure following revision surgery in breast cancer patients with a previous immediate implant-based breast reconstruction
}

\author{
A. Frisell ${ }^{1}$ (1) J. Lagergren ${ }^{1,2} \cdot$ M. Halle ${ }^{1,3} \cdot$ J. de Boniface ${ }^{1,2}$
}

Received: 7 June 2020 / Accepted: 1 September 2020 / Published online: 12 September 2020

(C) The Author(s) 2020

\begin{abstract}
Purpose The aim of the current study was to evaluate risk factors and timing of revision surgery following immediate implant-based breast reconstruction (IBR).

Methods This retrospective cohort included women with a previous therapeutic mastectomy and implant-based IBR who had undergone implant revision surgery between 2005 and 2015. Data were collected by medical chart review and registered in the Stockholm Breast Reconstruction Database. The primary endpoint was implant removal due to surgical complications, i.e. implant failure.

Results The cohort consisted of 475 women with 707 revisions in 542 breasts. Overall, 33 implants were removed due to complications. The implant failure rate (4.7\%) was lower without RT (2.4\%) compared to RT administered after mastectomy $(7.5 \%)$ and prior to IBR $(6.5 \%)(p=0.007)$. While post-mastectomy RT (OR 3.39, 95\% CI 1.53-7.53), smoking (OR 3.90, 95\% CI 1.76-8.65) and diabetes (OR 5.40, 95\% CI 1.05-27.85) were confirmed as risk factors, time from completion of RT (>9 months, 6-9 months, <6 months) was not (OR 3.17, 95\% CI 0.78-12.80, and OR 0.74, 95\% CI 0.20-2.71). Additional risk factors were a previous axillary clearance (OR 4.91, 95\% CI 2.09-11.53) and a history of a post-IBR infection (OR 15.52, 95\% CI 4.15-58.01, and OR 12.93, 95\% CI 3.04-55.12, for oral and intravenous antibiotics, respectively).

Conclusions Previous axillary clearance and a history of post-IBR infection emerged as novel risk factors for implant failure after revision surgery. While known risk factors were confirmed, time elapsed from RT completion to revision surgery did not influence the outcome in this analysis.
\end{abstract}

Keywords Implant exchange $\cdot$ Revision surgery $\cdot$ Implant failure $\cdot$ Implant removal

\section{Introduction}

In accordance to national and international guidelines, immediate breast reconstruction (IBR) should be offered [1] when discussing mastectomy with breast cancer patients. The most common surgical method for IBR is implant based, with increasing rates both in Sweden [2] and other

A. Frisell

axel.frisell@ki.se

1 Department of Molecular Medicine and Surgery, Karolinska Institutet, 17177 Solna, Stockholm, Sweden

2 Department of Surgery, Capio St. Göran's Hospital, Stockholm, Sweden

3 Reconstructive Plastic Surgery, Karolinska University Hospital, Stockholm, Sweden countries [3]. One of the most important factors when planning for implant-based IBR is previous or post-mastectomy radiotherapy (PMRT). Radiotherapy (RT) causes chronic inflammatory changes and tissue remodelling [4], and may result in capsular contracture and tissue fibrosis with deteriorated cosmetic outcome, psychological distress and pain as potential complications [5]. As it also negatively affects wound healing and tissue repair [4], it is acknowledged that any further ipsilateral revision surgery entering the implant cavity comes with a higher risk for wound complications and infection. Despite these negative effects, however, it is internationally agreed that PMRT poses no contraindication to IBR in the well-informed patient. In a previous publication from our group, as much as $77.7 \%$ of women receiving PMRT would recommend implant-based IBR to other women in their situation, while the corresponding figure was only $68.7 \%$ in women with RT prior to IBR [6]. 
Many women may prefer a potentially temporary implantbased reconstruction, followed by an optional change to an autologous tissue reconstruction, to a simple mastectomy combined with an external prosthesis. Other women may not have sufficient autologous tissue for a delayed reconstruction, and will thus be offered the choice between a skin- or nipple-sparing IBR and a delayed implant-based reconstruction after a simple mastectomy. The latter, however, is fraught with the same negative radiation effects if performed after PMRT.

The timing of implant exchange in the context of PMRT, i.e. replacing an initially placed tissue expander with a permanent fixed-volume implant, has been widely discussed $[7,8]$. Furthermore, the time necessary for early irradiation effects to settle before attempting revision surgery, and the association between time from PMRT to revision surgery are as yet debated [9-11]. The aim of this study was to analyse implant failure rates in irradiated versus non-irradiated patients, and identify temporal patterns to define the optimal time frame for scheduling implant revision surgery in the setting of PMRT after implant-based IBR in breast cancer patients.

\section{Patients and methods}

The primary endpoint of this retrospective cohort study was implant removal due to complications after post-IBR revision surgery, i.e. implant failure. To this end, all consecutive patients who had undergone ipsilateral breast implant revision surgery entering the implant cavity, e.g. implant exchange or capsulectomy, at Karolinska University Hospital between 2005 and 2015, and who had previously had a therapeutic mastectomy with implant-based IBR, were identified through their intervention codes. Smaller revision surgeries such as lipofilling, scar correction or nipple reconstruction were disregarded. In a second step, any purely prophylactic mastectomies or incorrectly coded patients were excluded by individual medical chart review. While the use of mesh/acellular dermal matrix (ADM) and prepectoral implant placement have been implemented in Stockholm in later years, there was only prepectoral placement during the studied time period. Only two reconstructions were assisted by ADM, rendering it impossible to draw any conclusions regarding specific associated risks and the impact of RT.

The aim of this study was to create a decisional aid for patient and surgeon prior to implant revision surgery, focusing on postoperative surgical complications. Patients who had their breast implants removed due to their own wish or during the process of converting an implant-based reconstruction into an autologous reconstruction were removed from the population, in order to avoid any bias regarding each patient's doctor's subjective evaluation (see Fig. 1).
Information on tumour characteristics, surgical procedures and oncological treatment with special detail regarding PMRT, complications and lifestyle factors were collected by individual medical chart review for each patient and registered in the retrospective Stockholm Breast Reconstruction Database, which is a pseudonymized digital database constructed in 2017. Cases were censored at the date of implant failure, and the date of the last revision surgery preceding implant failure was used for calculation of time from completion of PMRT to revision surgery as well as time from revision surgery to implant failure.

\section{Statistical analysis}

Categorical data are presented as numbers with their percentages, and continuous variables as median values with their range. For the comparison of categorical variables between the two groups of implant failure and no implant failure, the Chi Square or Fisher's exact tests, respectively, were used. Comparison of continuous variables in two groups was performed using the Mann-Whitney U test, and in more than two groups using the Kruskal-Wallis test. For tumour and treatment characteristics, data are presented per breast. The association between clinical covariates and the outcome per breast was assessed by univariable binary logistic regression with implant failure as the endpoint, presenting odds ratios and their respective $95 \%$ confidence intervals. Multivariable regression analysis was not deemed appropriate due to a low number of observed events. Implant failure rates were calculated per revision surgery in order to mirror the clinical situation of preoperative assessment before the planned surgery.

All data analysis was performed using SPSS ${ }^{\circledR}$ version 24 (IBM, Armonk, New York, USA). Statistical significance was set at the 0.05 level for all analyses.

\section{Results}

After the exclusion of prophylactic and incorrectly registered cases, 475 breast cancer patients (542 breasts) with a previous IBR were identified in whom 707 implant revision surgeries had been performed, see Fig. 1. Median follow-up time, i.e. time from revision surgery to medical chart review, was 95 months (range 2-215). For details on patient and tumour characteristics per breast, see Table 1.

Twenty-four breasts (4.4\%) had been irradiated between 1 and 25 years prior to IBR due to a previous breast cancer treated by breast conservation $(N=23)$ or due to lymphoma $(N=1)$. A further 223 breasts $(41.1 \%)$ had received post-mastectomy RT (PMRT), while 288 breasts (53.1\%) had never been irradiated. Information on irradiation was missing for 
Fig. 1 Flow chart for the creation of the final cohort of implant failure $(N=33)$ and no implant failure $(N=509)$ after revision surgery following a previous immediate implantbased breast reconstruction

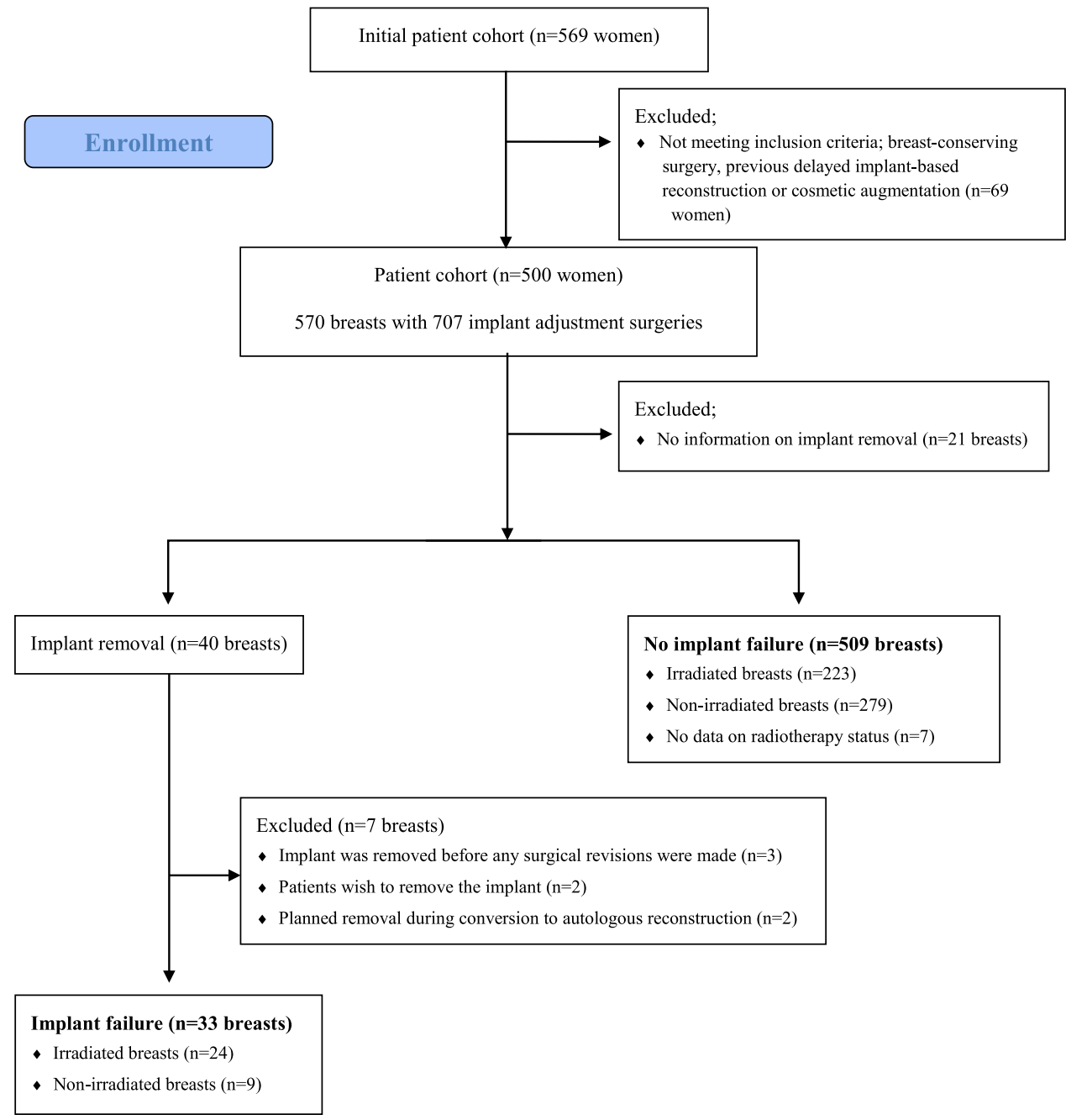

seven breasts. A total of 33 implants (one bilateral case of implant failure) were removed due to surgical complications. Since it is clinically more relevant to know the risk for each surgical intervention, not each breast, the implant failure rate was then calculated per revision surgery and was lowest in non-irradiated breasts ( 9 out of 375 surgeries, $2.4 \%$ ) and substantially higher following PMRT (22 out of 293 surgeries, $7.5 \%$ ) and if RT had been given prior to IBR ( 2 out of 31 surgeries, $6.5 \%$; overall $p=0.007)$. In most breasts $(72.9 \%)$, only one revision surgery had been performed, with a median number of revision surgeries entering the implant cavity of one (range 1-5) per breast during follow-up time. The median time from the latest revision to implant failure was 2 months (1-153). Implant failure occurred in 13 cases $(8 \%)$ if revision surgery had been performed after more than 9 months, in 3 cases $(6 \%)$ if revision was undertaken after 6-9 months, and in $3(21.4 \%)$ of women where it was done after less than 6 months from completion of RT. Probably due to the low event rate and few cases with short time between RT completion and first revision surgery, this difference was not statistically significant ( $p=0.171$; see Table 2$)$. Unadjusted risk factors for implant failure, calculated per breast, are presented in Table 3. Known risk factors such as current smoking and diabetes were confirmed in the present cohort. Interestingly, postoperative infection reported after the initial IBR increased the risk of implant failure after revision surgery significantly, whether the previous infection was diagnosed based on suspicious clinical signs only ( $p=0.005$ ) or confirmed by bacterial cultures and/or elevated inflammatory markers such as the $\mathrm{C}$-reactive protein (CRP) $(p<0.001)$. This is noteworthy since these infections had obviously not resulted in an implant failure during the postoperative period following IBR. As expected, PMRT was a significant risk factor for implant failure. Looking at the RT target, however, risk for implant removal was only increased if locoregional RT was given, not if it only targeted the chest wall. Likewise, the performance of an axillary clearance, intimately associated with node positivity, increased the risk fivefold. In order to differentiate between the effect of locoregional RT and that of axillary clearance, both covariates were entered into the same regression model: Here, locoregional RT lost its significance (OR 2.11, 95\% CI 0.85-5.24) when compared with no RT, while axillary clearance retained its significant 
Table 1 Tumour and treatment characteristics per operated breast

\begin{tabular}{|c|c|}
\hline & Breasts $(n=542)$ \\
\hline \multicolumn{2}{|l|}{ Invasiveness } \\
\hline In situ only & 105 (19.4) \\
\hline Mixed & $277(51.1)$ \\
\hline Invasive only & $108(19.9)$ \\
\hline Missing & $52(9.6)$ \\
\hline \multicolumn{2}{|l|}{ Histopathological tumour size* } \\
\hline Tis (in situ only) & $135(29.5)$ \\
\hline $\mathrm{T} 1(\leq 20 \mathrm{~mm})$ & $55(12.0)$ \\
\hline $\mathrm{T} 2(21-50 \mathrm{~mm})$ & $112(24.5)$ \\
\hline $\mathrm{T} 3 / \mathrm{T} 4$ (>50 mm/locally advanced) & $86(18.8)$ \\
\hline Missing & $69(15.2)$ \\
\hline \multicolumn{2}{|l|}{ Type of invasive cancer } \\
\hline Ductal & $302(55.7)$ \\
\hline Lobular & $59(10.9)$ \\
\hline Mixed & $7(1.3)$ \\
\hline Other type & $4(0.7)$ \\
\hline Missing & $170(31.4)$ \\
\hline \multicolumn{2}{|c|}{$\begin{array}{l}\text { Histopathological size of largest axillary metas- } \\
\text { tasis* }\end{array}$} \\
\hline None (pN0) & $315(68.9)$ \\
\hline ITC (pNOi+) & $19(4.2)$ \\
\hline Micrometastasis (pN1mic) & $10(2.2)$ \\
\hline Macrometastasis (pN1-3) & $103(22.5)$ \\
\hline Missing & $10(2.2)$ \\
\hline \multicolumn{2}{|l|}{ Chemotherapy** } \\
\hline Yes & $234(43.2)$ \\
\hline No & $287(53.0)$ \\
\hline Missing & $21(3.9)$ \\
\hline \multicolumn{2}{|l|}{ Endocrine therapy** } \\
\hline Yes & $348(64.2)$ \\
\hline No & $180(33.2)$ \\
\hline Missing & $14(2.6)$ \\
\hline \multicolumn{2}{|l|}{ Anti-HER2 therapy** } \\
\hline Yes & $86(15.9)$ \\
\hline No & $450(83.0)$ \\
\hline Missing & $6(1.1)$ \\
\hline
\end{tabular}

Values in parentheses are percentages unless indicated otherwise

*Patients with neoadjuvant treatment excluded $(n=85)$,

**Received as adjuvant or neoadjuvant treatment

negative effect on the risk of implant failure (OR 2.99, 95\% CI 1.08-8.27).

\section{Discussion}

The optimal timing of revision surgery after IBR, especially in irradiated patients, remains a question of clinical assessment for most surgeons. While irradiation posed a significant
Table 2 Radiotherapy details per operated breast $(N=542)$

\begin{tabular}{llll}
\hline & $\begin{array}{l}\text { Implant } \\
\text { failure } \\
(n=33)\end{array}$ & $\begin{array}{l}\text { No implant } \\
\text { failure } \\
(n=509)\end{array}$ & $p$ \\
\hline Radiotherapy & $2(8.3)$ & $22(91.7)$ & 0.007 \\
Yes, prior to IBR & $22(9.9)$ & $201(90.1)$ & \\
Yes, after IBR & $9(3.1)$ & $279(96.9)$ & \\
None & 0 & 7 & 0.018 \\
Missing & & & \\
Type of adjuvant radiotherapy* & & \\
Local & $3(3.7)$ & $79(96.3)$ & \\
Locoregional & $19(13.5)$ & $122(86.5)$ & \\
Missing & 0 & 0 & \\
Radiotherapy dose/fractions* & & & \\
46 Gy/23 fractions & $2(11.1)$ & $16(88.9)$ & \\
50 Gy/25 fractions & $20(10.1)$ & $178(89.9)$ & \\
Other & 0 & 7 & 0.171 \\
Missing & 0 & 0 & \\
Months from end of radiother- & & & \\
apy to first surgical revision & & $1507(92.0)$ & \\
$>9$ months & $13(8.0)$ & $15(78.6)$ & \\
6-9 months & $3(6.0)$ & $47(94.0)$ & \\
$<6$ months & $3(21.4)$ & 11 & \\
Missing & 5 & 15 & \\
\hline
\end{tabular}

$I B R$ immediate implant-based breast reconstruction

*Patients who had received other than adjuvant RT after IBR were excluded

risk for implant failure following revision surgery, we could not find support for a clinical role of timing of the revision surgery in relation to completed RT, probably because of few events and a generally long interval between RT and first revision surgery. Additional factors like the irradiated target volume, previous axillary clearance and a history of infection after IBR appear important to take into consideration.

In Sweden, revision surgery entering the implant cavity after a previous IBR is only undertaken once RT has been completed, and a minimum time of 6 months between RT completion and revision surgery has long been recommended. Santosa et al. showed that there was no difference in complication rates among women who received PMRT onto an expander or after the exchange to a permanent implant [12]. For women without indications for RT, revision surgery (most commonly an exchange of the implant) can be performed as early as 1 month after full expansion of the expander device $[11,13]$. The current recommendations of exchange to a permanent implant in the setting of PMRT range from 3 to 6 months after RT $[8,14]$. However, Peled et al. showed that the implant failure rate significantly decreased from 22.4 to $7.7 \%(p=0.036)$ if more than 6 months elapsed between the completion of PMRT and the exchange procedure [8]. Noteworthy, the current study 
Table 3 Univariable logistic regression analysis with implant failure after revision surgery as the endpoint

\begin{tabular}{|c|c|c|c|c|}
\hline & \multicolumn{4}{|c|}{ Univariable } \\
\hline & All cases & Implant failure & Odds ratio & $p$ \\
\hline Total number of breasts & 542 & 33 & & \\
\hline \multicolumn{5}{|l|}{ Age (years) at IBR } \\
\hline$<50$ & 319 & 21 & 1.00 (reference) & \\
\hline $50-60$ & 163 & 10 & $0.93(0.43-2.02)$ & 0.850 \\
\hline$>60$ & 60 & 2 & $0.49(0.11-2.14)$ & 0.343 \\
\hline Missing & 0 & 0 & & \\
\hline \multicolumn{5}{|c|}{ Histopathological tumour stage } \\
\hline Tis (in situ only) & 135 & 11 & 1.00 (reference) & \\
\hline $\mathrm{T} 1(\leq 20 \mathrm{~mm})$ & 55 & 1 & $0.21(0.03-1.66)$ & 0.138 \\
\hline $\mathrm{T} 2(21-50 \mathrm{~mm})$ & 112 & 4 & $0.42(0.13-1.35)$ & 0.144 \\
\hline $\mathrm{T} 3 / \mathrm{T} 4(>50 \mathrm{~mm})$ & 86 & 5 & $0.70(0.23-2.08$ & 0.516 \\
\hline Missing & 154 & 12 & & \\
\hline \multicolumn{5}{|c|}{ Histopathological nodal stage } \\
\hline Node negative & 407 & 17 & 1.00 (reference) & \\
\hline Node positive & 111 & 14 & $3.31(1.58-6.95)$ & 0.002 \\
\hline Missing & 24 & 2 & & \\
\hline \multicolumn{5}{|l|}{ Axillary clearance } \\
\hline No & 290 & 7 & 1.00 (reference) & \\
\hline Yes & 240 & 26 & $4.91(2.09-11.53)$ & $<0.001$ \\
\hline Missing & 12 & 0 & & \\
\hline \multicolumn{5}{|l|}{ Type of implant } \\
\hline Temporary expander & 33 & 1 & 1.00 (reference) & \\
\hline Permanent expander & 434 & 29 & $2.29(0.30-17.37)$ & 0.422 \\
\hline Fixed-volume implant & 68 & 2 & $0.97(0.09-11.10)$ & 0.980 \\
\hline Missing & 7 & 1 & & \\
\hline \multicolumn{5}{|l|}{ Final implant volume* } \\
\hline$<300 \mathrm{cc}$ & 151 & 8 & 1.00 (reference) & \\
\hline $300-400 \mathrm{cc}$ & 265 & 12 & $0.85(0.34-2.12)$ & 0.724 \\
\hline$>400 \mathrm{cc}$ & 118 & 10 & $1.66(0.63-4.33)$ & 0.305 \\
\hline Missing & 8 & 3 & & \\
\hline \multicolumn{5}{|l|}{ Radiotherapy } \\
\hline None & 288 & 9 & 1.00 (reference) & \\
\hline Yes, prior to IBR & 24 & 2 & $2.82(0.57-13.85)$ & 0.202 \\
\hline Yes, after IBR & 223 & 22 & $3.39(1.53-7.53)$ & 0.003 \\
\hline Missing & 7 & 0 & & \\
\hline \multicolumn{5}{|c|}{ Type of adjuvant radiotherapy** } \\
\hline Local & 82 & 3 & 1.00 (reference) & \\
\hline Locoregional & 141 & 19 & $4.10(1.18-14.32)$ & 0.027 \\
\hline Missing & 0 & 0 & & \\
\hline \multicolumn{5}{|c|}{ Radiotherapy dose/fractions** } \\
\hline $46 \mathrm{~Gy} / 23$ fractions & 18 & 2 & 1.00 (reference) & \\
\hline $50 \mathrm{~Gy} / 25$ fractions & 198 & 20 & $0.90(0.19-4.20)$ & 0.892 \\
\hline Missing/other & 7 & 0 & & \\
\hline \multicolumn{5}{|c|}{ Months from end of radiotherapy to first surgical revision } \\
\hline$>9$ months & 163 & 13 & 1.00 (reference) & \\
\hline $6-9$ months & 50 & 3 & $3.17(0.78-12.80)$ & 0.106 \\
\hline$<6$ months & 14 & 3 & $0.74(0.20-2.71)$ & 0.651 \\
\hline Missing & 20 & 5 & & \\
\hline
\end{tabular}


Table 3 (continued)

\begin{tabular}{|c|c|c|c|c|}
\hline & \multicolumn{4}{|c|}{ Univariable } \\
\hline & All cases & Implant failure & Odds ratio & $p$ \\
\hline \multicolumn{5}{|l|}{ Postoperative infection within 30 days after IBR } \\
\hline No infection & 398 & 10 & 1.00 (reference) & \\
\hline Clinical signs of infection, oral antibiotic treatment & 72 & 7 & $4.18(1.54-11.37)$ & 0.005 \\
\hline Confirmed infection, oral antibiotic treatment ${ }^{\mathrm{a}}$ & 14 & 4 & $15.52(4.15-58.01)$ & $<0.001$ \\
\hline Confirmed infection, intravenous antibiotic treatment ${ }^{\mathrm{a}}$ & 12 & 3 & $12.93(3.04-55.12)$ & 0.001 \\
\hline Missing & 46 & 9 & & \\
\hline \multicolumn{5}{|c|}{ Postoperative complication with return to theatre (within 30 days) after IBR } \\
\hline No & 489 & 24 & 1.00 (reference) & \\
\hline Yes & 11 & 1 & $1.94(0.24-15.76)$ & 0.536 \\
\hline Missing & 42 & 8 & & \\
\hline \multicolumn{5}{|l|}{ Postoperative complication without return to theatre after IBR } \\
\hline None & 464 & 23 & 1.00 (reference) & \\
\hline Seroma & 44 & 4 & $1.92(0.63-5.82)$ & 0.250 \\
\hline Infection & 5 & 2 & $12.78(2.04-80.30$ & 0.007 \\
\hline Bleeding & 8 & 1 & $2.74(0.32-23.21)$ & 0.355 \\
\hline Skin necrosis & 7 & 1 & $3.20(0.37-27.66)$ & 0.291 \\
\hline$\geq 2$ complications & 14 & 2 & $3.20(0.68-15.13)$ & 0.143 \\
\hline Missing & 0 & 0 & & \\
\hline \multicolumn{5}{|l|}{ Previous revision surgery performed } \\
\hline No & 395 & 22 & 1.00 (reference) & \\
\hline Yes & 147 & 11 & $1.37(0.65-2.90)$ & 0.409 \\
\hline Missing & 0 & 0 & & \\
\hline \multicolumn{5}{|l|}{$\mathrm{BMI}^{\mathrm{c}}$} \\
\hline Normal (18.5-30) & 438 & 18 & 1.00 (reference) & \\
\hline Underweight $(<18.5)$ & 8 & 1 & $3.33(0.39-28.55)$ & 0.272 \\
\hline Overweight $(>30)$ & 23 & 3 & $3.50(0.95-12-87)$ & 0.059 \\
\hline Missing & 73 & 11 & & \\
\hline \multicolumn{5}{|l|}{ Smoking $^{\mathrm{c}}$} \\
\hline Never smoked & 383 & 19 & 1.00 (reference) & \\
\hline Currently smoking & 65 & 11 & $3.90(1.76-8.65)$ & 0.001 \\
\hline Former smoker & 73 & 2 & $0.54(0.12-2.37)$ & 0.414 \\
\hline Missing & 21 & 1 & & \\
\hline \multicolumn{5}{|l|}{ Immunosuppressive treatment $^{\mathrm{c}}$} \\
\hline No & 498 & 31 & 1.00 (reference) & \\
\hline Yes & 9 & 2 & $3.57(0.74-17.24)$ & 0.113 \\
\hline Missing & 35 & 0 & & \\
\hline \multicolumn{5}{|l|}{ Antihypertensive medication ${ }^{c}$} \\
\hline No & 454 & 26 & 1.00 (reference) & \\
\hline Yes & 42 & 5 & $2.08(0.76-5.70)$ & 0.155 \\
\hline Missing & 46 & 2 & & \\
\hline \multicolumn{5}{|l|}{ Diabetes $^{\mathrm{c}}$} \\
\hline No & 502 & 31 & 1.00 (reference) & \\
\hline Yes, with medication ${ }^{\mathrm{b}}$ & 6 & 2 & $5.40(1.05-27.85)$ & 0.044 \\
\hline Missing & 34 & 0 & & \\
\hline
\end{tabular}

Each case represents one operated breast

IBR immediate implant-based breast reconstruction

*Final expander volume or fixed-volume implant size

**Reporting only patients who had received RT after IBR

${ }^{a}$ Confirmed by positive bacterial cultures and/or elevated C-reactive protein

${ }^{\mathrm{b}}$ Including oral medication and/or insulin

${ }^{c}$ Registered at the time of IBR, not at implant revision surgery 
is one of few studies conducted in a non-two-stage breast reconstruction setting with the aim to evaluate temporal aspects of revision following RT. More time has therefore passed between completion of RT and revision surgery and comparison is thus difficult. Especially Peled et al. compared very early implant exchange ( 3 months) with 6 months (at a median of 14 weeks and 37 weeks, respectively) after completion of RT in a planned two-stage breast reconstruction setting. In the present cohort, however, a majority of the patients received a permanent expander without any timeline for a planned implant exchange, where the influence of time seems to be less important, unlike many of the centres that have studied a planned revision in a two-stage setting.

Axillary treatment, in Sweden including both axillary clearance and locoregional radiotherapy in patients with any axillary macrometastases outside of clinical trials, significantly increased the risk of implant failure. Interestingly, it was the axillary surgery that carried the significant increase in risk when adjusted for locoregional RT. In agreement with this, long-term negative consequences such as arm lymphoedema were significantly stronger associated with axillary surgery than with locoregional RT [15]. It is likely that scarring and fibrotic changes in the axilla decrease lymphatic drainage from the remaining chest wall, leading to delayed wound healing and an enhanced susceptibility to infection [16].

Our results show that even a transient clinically diagnosed infection after the initial IBR was a strong predictor of implant failure after the revision procedure. This is probably due to residual subclinical infection despite clinically successful antibiotic treatment, inducing capsular contraction [17]; remaining subclinical bacterial presence in capsular tissue or the implant coating itself may be re-activated during revision surgery, possibly explaining the increased risk for implant loss such a long time after IBR itself. While the cumulative infection rate was high, it needs to be taken into account that even the slightest suspicion of infection, without any supporting proofs, was considered. In such cases, antibiotics may well only be administered for sheer safety since an unacknowledged infection would have devastating consequences on the implant reconstruction. Unfortunately, there was no confirmative information regarding new clinical signs of infection after revision surgery, which limits the strength of this hypothesis. It would be interesting to test the hypothesis whether prolonged prophylactic antibiotic usage in the setting of high-risk revision surgery could decrease implant failure rates.

Limitations of the study need to be acknowledged. First, in retrospective studies, there is a limitation in the extent of information registered in medical charts. Although our patient cohort is relatively large, the number of events, i.e. implant failures, was surprisingly low, which made advanced statistical adjustments unfeasible. On the other hand, this same fact should underline that revision surgery is a safe procedure even in the face of a number of risk factors identified. Second, since we only selected implant removal due to surgical complications but not due to discomfort, inferior cosmetic results or patient wish (often resulting in the conversion of an implantbased reconstruction to an autologous method), the rate of implant removal may have been underestimated. While the present analysis focussed on surgical complications as the reason for implant failure, we will in an upcoming analysis report on rates of conversion to autologous breast reconstruction, which can well be counted towards implant failure, too. Third, clinical factors such as postoperative complications, BMI and smoking were registered for IBR, not for the subsequent implant revision surgery. Likewise, all included patients had at least one revision surgery, and thus, women who opted for an autologous conversion without any previous attempt at revision were not registered. Since these alternative outcomes also carry significant clinical importance, the overall implant removal should be further explored in future analyses.

Acknowledgements $\mathrm{JdB}$ is supported by a Young Clinical Investigator's Award from the Swedish Cancer Society. This study received financial support from the Percy Falk Foundation and the Swedish Breast Cancer Association.

Funding Open access funding provided by Karolinska Institute. The study received funding from the Swedish Breast Cancer Association (BRO). The paper is not based on a previous communication to a society or meeting.

Data availability The datasets generated and/or analysed during the current study are not publicly available due to confidentiality reasons regulated by Swedish law. Data can be requested from the register holder.

\section{Compliance with ethical standards}

Conflict of interest Axel Frisell declares that he has no conflict of interest. Jakob Lagergren declares that he has no conflict of interest. Martin Halle declares that he has no conflict of interest. Jana de Boniface declares that she has no conflict of interest.

Ethical approval The original study was approved by the Ethics Review Board at Karolinska Institutet, Stockholm, in 2016 (2016/1374-32). In this study did only involve human participants. All procedures performed in studies involving human participants were in accordance with the ethical standards of the institutional and/or national research committee and with the 1964 Helsinki declaration and its later amendments or comparable ethical standards.

Informed consent The Ethical Review Board at Karolinska Institutet determined that individual informed consent was not required for this type of study.

Open Access This article is licensed under a Creative Commons Attribution 4.0 International License, which permits use, sharing, adaptation, distribution and reproduction in any medium or format, as long as you give appropriate credit to the original author(s) and the source, provide a link to the Creative Commons licence, and indicate if changes 
were made. The images or other third party material in this article are included in the article's Creative Commons licence, unless indicated otherwise in a credit line to the material. If material is not included in the article's Creative Commons licence and your intended use is not permitted by statutory regulation or exceeds the permitted use, you will need to obtain permission directly from the copyright holder. To view a copy of this licence, visit http://creativecommons.org/licenses/by/4.0/.

\section{References}

1. Nationella riktlinjer för bröstcancer (National guidelines of breast cancer in Sweden). https://www.socialstyrelsen.se/globalassets/ sharepointdokument/artikelkatalog/nationella-riktlinjer/nr-cance r-vetenskapligt-underlag-brostcancer.pdf. Accessed Nov 2019

2. Årsrapport 2018 från Nationella Bröstcancerregistret (Annual report from the National Breast Cancer Registry in 2018). https:// www.cancercentrum.se/globalassets/cancerdiagnoser/brost/kvali tetsregister/sammanfattning-och-vagledning-till-interaktiva-rappo rten-for-2018.pdf. Accessed Sept 2019

3. Razdan SN, Cordeiro MPG, Albornoz CR, Disa JJ, Panchal $\mathrm{HJ}$ et al (2017) National breast reconstruction utilization in the setting of postmastectomy radiotherapy. J Reconstr Microsurg 1(212):312-317

4. Stone HB, Coleman CN, Anscher MS, McBride WH (2003) Effects of radiation on normal tissue: consequences and mechanisms. Lancet Oncol 4(9):529-536

5. Sheehan J, Sherman AK, Lam T (2008) Association of information satisfaction, psychological distress and monitoring coping style with post-decision regret following breast reconstruction. Psychooncology 17(July 2006):363-372

6. Eriksson M, Anveden L, Celebioglu F, Dahlberg K, Meldahl I, Lagergren J et al (2013) Radiotherapy in implant-based immediate breast reconstruction: Risk factors, surgical outcomes, and patient-reported outcome measures in a large Swedish multicenter cohort. Breast Cancer Res Treat 142(3):591-601

7. Lee KT, Mun GH (2017) Optimal sequencing of postmastectomy radiotherapy and two stages of prosthetic reconstruction: a metaanalysis. Ann Surg Oncol 24(5):1262-1268
8. Peled AW, Foster RD, Esserman LJ, Park CC, Shelley Hwang E, Fowble B (2012) Increasing the time to expander-implant exchange after postmastectomy radiation therapy reduces expander-implant failure. Plast Reconstr Surg 130(3):503-509

9. Nava MB, Pennati AE, Lozza L, Spano A, Zambetti M (2011) Outcome of different timings of radiotherapy in implant-based breast reconstructions. Plast Reconstr Surg 128(2):353-359

10. Foster RD, Esserman LJ, Hwang ES (2012) Increasing the time to expander-implant exchange after postmastectomy radiation therapy reduces expander-implant failure. Plast Reconstr Surg 130(3):503-509

11. Cordeiro PG, Albornoz CR, McCormick B, Hudis CA, Hu Q, Heerdt A et al (2015) What is the optimum timing of postmastectomy radiotherapy in two-stage prosthetic reconstruction: radiation to the tissue expander or permanent implant? Plast Reconstr Surg 135(6):1509-1517

12. Santosa KB, Chen X, Qi J, Ballard TNS, Kim HM, Hamill JB et al (2016) Postmastectomy radiation therapy and two-stage implantbased breast reconstruction: is there a better time to irradiate? Plast Reconstr Surg 138(4):761-769

13. Weintraub JL, Kahn DM (2008) The timing of implant exchange in the development of capsular contracture after breast reconstruction. Eplasty 8:e31

14. Pusic AL, Cordeiro PG (2004) Breast reconstruction with tissue expanders and implants: a practical guide to immediate and delayed reconstruction. Semin Plast Surg 18(2):71-77

15. Sackey H, Magnuson A, Sandelin K, Liljegren G, Bergkvist L et al (2014) Arm lymphoedema after axillary surgery in women with invasive breast cancer. Br J Surg 101(4):390-397

16. Joy MT, Rich MD, Moyer KE (2018) Axillary lymphadenectomy and wound complications in implant-based breast reconstruction. Ann Plast Surg 81(3):280-283

17. Lalani $T$ (2018) Breast implant infections: an update. Infect Dis Clin North Am 32(4):877-884. https://doi.org/10.1016/j. idc.2018.06.007

Publisher's Note Springer Nature remains neutral with regard to jurisdictional claims in published maps and institutional affiliations. 